\title{
SARMIENTO, TESTIGO Y TESTIMONIO DE LA SOCIEDAD DE SANTIAGO
}

\author{
POR \\ LUIS ALBERTO ROMERO \\ Consejo Nacional de Investigaciones Cientificas y Técnicas \\ (Buenos Aires)
}

A fines de 1840, Sarmiento se instala en Santiago de Chile e inicia un exilio que habría de ser decisivo en su vida. Allí aprende los oficios de escritor, de pedagogo, de político, de reformador. Las ideas vagas, confusas, desmedidas que tiene en 1840 , hechas de lecturas todavía no asentadas ni confrontadas con la realidad, ya se habían conformado en 1845, cuando escribe Facundo y formula una explicación de la «historia profunda» de la Argentina. Esos cinco años son, sin duda, fundamentales en la formación de sus ideas ${ }^{1}$.

De las múltiples experiencias con que se conformó una forma mentis singular, hay una que creo poder identificar: la que surge de la vida en una ciudad relativamente importante, que era a la vez la capital de un Estado firme y asentado. Así como Valparaíso se reconoce en las ideas de Alberdi, me parece claro que Santiago lo está en las de Sarmiento. Hasta entonces no había conocido una ciudad importante: sólo pequeñas capitales provinciales como San Juan o Mendoza y una fugaz visita a Valparaíso. Por esos años, sus reflexiones acerca de la ciudad, que él asoció con la civilización, y que aparecen totalmente maduras en $\mathrm{Fa}$ cundo, tienen como soporte, junto con aquellas pequeñas ciudades agrícolas y virtuosas como las antiguas, a la más moderna, patricia y europeizada capital de Chile ${ }^{2}$.

${ }^{1}$ Así lo destaca Allison William Bunkley en Vida de Sarmiento (Buenos Aires: EUDEBA, 1966), p. 120.

${ }^{2}$ Sobre esta influencia, véase el excelente trabajo de Natalio Botana La tradición republicana (Buenos Aires: Sudamericana, 1984), para quien la comprensión cabal de la sociedad moderna sólo será fruto de los viajes a Europa y, sobre todo, a Estados Unidos, mientras que la imagen de la sociedad presente en Facundo se ha elaborado sobre la experiencia de la ciudad agrícola. 
Esa experiencia está presente, de un modo $\mathfrak{u}$ otro, en todos sus escritos de esa época, pero de un modo singular en los artículos periodísticos, aparecidos en El Mercurio de Valparaíso y El Progreso, primer periódico santiaguino, que él fundó. Muchos de ellos se ajustan a un género entonces prestigioso: el costumbrismo, impuesto por los españoles Larra, Mesonero Romanos o Fray Gerundio, y desarrollado en el Plata y Chile por Alberdi, Echeverría, Jotabeche, Blest Gana y otros. En sus textos costumbristas, Sarmiento mantiene el equilibrio propio de Larra, entre el cuadro vivaz y pintoresco y la crítica social y política (que Jotabeche y Alberdi rompen, en uno y otro sentido), aunque con frecuencia avanza, sin transiciones bruscas, por la segunda línea en artículos declaradamente de análisis y tesis ${ }^{3}$.

Este tipo de textos le sirve para enfrentarse con una ciudad que, por esos años, empieza a crecer y transformarse. Sarmiento se revela como un testigo, más lúcido y perspicaz que sus contemporáneos, de unos cambios que sólo dos décadas después se impondrán en la conciencia colectiva, y también como un analista agudo de sus mecanismos recónditos. Es posible reconstruir esa transformación inicial de la ciudad con la guía de los textos de Sarmiento.

Pero, además, en ellos se dibuja la trama social y cultural de una de esas sociedades patricias características de las ciudades hispanoamericanas de mediados del siglo pasado. Aquí, el testigo lúcido es, a la vez, testimonio transparente de la imagen que las elites patricias tienen de la sociedad, de sus sectores populares, de los complejos lazos que los ligan y de los conflictos que los separan, conformando esa singular relación de escisión e integración. Su testimonio resulta atrayente y revelador porque, a la vez, Sarmiento es capaz de trascender la perspectiva de sus pares, iluminar con una mirada comprensiva y hasta simpática a los sectores plebeyos, entender los conflictos y trazar, por encima de ambas partes de la sociedad, el proyecto de otra, moderna y progresista. Así, esa singular mezcla de testigo y testimonio, de hombre de su mundo y de su siglo, convierten a este formidable escritor en una fuente, igualmente formidable, para el historiador ${ }^{4}$.

\footnotetext{
${ }^{3}$ Paul Verdevoye, Domingo Faustino Sarmiento, éducateur et publiciste (entre 1839 ef 1852) (Paris: Institut des Hautes Études de l’Amérique Latine, 1963), p. 91.

${ }^{4} \mathrm{Mi}$ interés por los textos de Sarmiento sobre Santiago se originó precisamente en un estudio que estoy realizando sobre los sectores populares de la capital chilena en el siglo XIX, para el que encontré en ellos una guía excelente. Puede verse mi trabajo «Urbanización y sectores populares: Santiago de Chile, 1830-1875», en EURE, Revista Latinoamericana de Estudios Urbanos Regionales, XI, 34 (Santiago de Chile, octubre de 1984). Y también La «Sociedad de la Igualdad». Los artesanos de Santia-
} 


\section{EL TESTIGO}

En las décadas siguientes a la emancipación, la capital de Chile creció significativamente, y a mediados de siglo era ya una ciudad de unos 90.000 habitantes ${ }^{5}$. Residencial y burocrática, se nutría con la acción de un Estado que estaba afirmándose y expandía lentamente sus funciones, pero también con la prosperidad comercial de Valparaíso, el desarrollo minero del Norte Chico y, a fines de los años cuarenta, la incipiente prosperidad agrícola vinculada con el «boom» californiano. Hacendados, comerciantes, mineros y funcionarios se congregaban en la capital, remozaban sus viviendas, refinaban sus costumbres y se abrían tímidamente a los usos e ideas europeos. Junto a ellos crecía su habitual complemento: los decentes pobres, los artesanos, vendedores, ambulantes, domésticos y muchos otros sin oficio fijo, que se congregaban en los nuevos suburbios de la ciudad.

Los aspectos más visibles de esta transformación fueron registrados por los contemporáneos. La mercantilización de la sociedad, la europeización de sus costumbres y el impacto de las ideas románticas se registran extensamente en Martín Rivas, de Blest Gana. Jotabeche percibió algunos aspectos de las migraciones y la formación de los nuevos suburbios. El intendente Miguel de la Barra, particularmente perspicaz, intuyó la magnitud de la migración rural y algunos de sus efectos sociales, pero en ningún caso, con excepción de Sarmiento, se encuentra una explicación que articule estos diferentes procesos y plantee sus relaciones profundas ${ }^{6}$.

Lo primero que llama la atención es la temprana percepción del cre-

go de Chile y sus primeras experiencias politicas, 1820-1851 (Buenos Aires: Editorial del Instituto T. Di Tella, 1978).

${ }^{5}$ Ese crecimiento, menor que el de Valparaíso, superaba al de la mayoría de las capitales hispanoamericanas. Hacia 1823 se estimaba su población en unas 35.000 personas, cifra doblada largamente dos décadas después. Cfr. Richard M. Morse, Las ciudades latinoamericanas, t. II (México: Sep Setentas, 1973), p. 29.

'Alberto Blest Gana, Martín Rivas, primera edición, 1862, y Costumbres y viajes. Páginas olvidadas (escritas entre 1853-1864) (Santiago de Chile: Difusión, 1947); José Joaquín Vallejo (Jotabeche), «El provinciano», «El provinciano en Santiago» y «El provinciano renegado», en Artículos y estudios de costumbres chilenas (18421847) (Santiago de Chile: Biblioteca Chilena, 1885); Memoria del Intendente de Santiago Miguel de la Barra (Santiago, 1846). Dice el intendente De la Barra: «Es una peculiaridad de este departamento la atracción que la capital ejerce sobre todos los puntos de la República. Por este medio pone a contribución no sólo a los departamentos de la provincia, sino a las provincias en general, que vienen a vaciar en los alrededores de la capital una inmensa superabundancia de población. Esta aglomeración de gentes miserables y sin industria para procurarse medios honrados de subsistencia aumenta el número de criminales y hace necesaria una particular contracción de la Intendencia para prevenir y perseguir sus atentados.» 
cimiento de la ciudad, que «es aún más rápido de un tiempo a esta parte, dejándose percibir fácilmente en la aumentación espontánea de casas, calles, barrios enteros, que antes no existían. Por todos los ángulos de la ciudad se nota esta extraordinaria expansión de la población. Las chimbas se han extendido, las rancherías llamadas huangulies, que hay en todos los suburbios, tienen multitud de casillas y callejuelas, como otros tantos villorrios» ${ }^{7}$. Por esos años se estaban formando ya los abigarrados rancheríos del bajo Yungay y del barrio Sur, que por entonces ya alcanzaba el canal San Miguel (la actual avenida Matta), pero su existencia, así como los problemas sanitarios, edilicios y sociales que implicaba, sólo aparece en la conciencia pública en los años sesenta, hasta que se instala definitivamente cuando, en 1872, Vicuña Mackenna la coloca definitivamente en el centro de las discusiones de lo que empezaba a llamarse la «cuestión social» ${ }^{8}$.

Luego de las controversias de 1870 sobre la migración de jornaleros al Perú, y sobre todo a partir del clásico texto de Orrego Luco ${ }^{9}$, este problema siempre se planteó - - hasta hoy, inclusive- en relación con la situación de los inquilinos, las migraciones, los factores de atracción y, particularmente, los problemas de desocupación y ocupación en el campo y en la ciudad. Estas articulaciones ya están presentes, a veces desarrolladas y otras esbozadas, en los textos de Sarmiento. Una de las causas de la emigración que descubre son las expectativas generadas por la gran ciudad, pese a que ni la industria ni el comercio pueden dar ocupación a todos. La ciudad atrae por «la multitud de pequeños modos de vivir, que son consiguientes a la complicación de necesidades que hay que satisfacer en ella» y «el atractivo del espectáculo variado de un pueblo

${ }^{7}$ «Sociedad de industria y población. IV: Santiago», en El Progreso, 19 y 22 de diciembre de 1842 (en adelante: «Santiago»). Este artículo no aparece en las Obras completas, compiladas y editadas entre 1885 y 1903 . Tampoco es registrado por P. Verdevoye en su bibliografía de Sarmiento, confeccionada sobre la base de las Obras completas y de los artículos periodísticos iniciados por Sarmiento en sus ejemplares de los periódicos. Sin embargo, la edición de las Obras incluye el primer artículo de esta serie (vol. XXIII, p. 189). Me parece que la autoría de Sarmiento es indudable, no sólo por su estilo, sino por ideas y hasta párrafos similares a los que se encuentran en «La villa de Yungay», "Aprendices de imprenta» y otros.

${ }^{8}$ Benjamín Vicuña Mackenna, La transformación de Santiago (1872). El valor de este texto ha sido destacado por Armando de Ramón en «Suburbios y arrabales en un área metropolitana. El caso de Santiago de Chile, 1872-1932», en J. E. Hardoy y R. Schaedel, Ensayos histórico-sociales sobre la urbanización en América Latina (Buenos Aires: Ediciones SIAP, 1978). Véase también mi trabajo «Condiciones de vida de los sectores populares en Santiago de Chile, 1840-1895: vivienda y salud», en Nueva Historia, Revista de Historia de Chile, núm. 9 (Londres, 1984).

${ }^{9}$ Augusto Orrego Luco, La cuestión social en Chile (Santiago, 1884). 
grande, que por sí solo produce emociones» ${ }^{10}$. Esta explicación se combina con otra, de carácter más estructural: la saturación del Valle central. La tierra está ya totalmente ocupada, de modo que «la misma estagnación de las provincias es la causa del exceso de movimiento en la capital». Se integra, finalmente, con otra que atiende a las características de los migrantes. Para De la Barra -el único que en este momento vio con claridad ese fenómeno-, éstos semejan a hordas hambrientas y desesperadas. Sarmiento, en cambio, destaca entre ellos el predominio de los jóvenes, subraya la importancia de una cierta aptitud o calificación para migrar y señala las etapas, en las aldeas o ciudades de provincia, en las que se agregan nuevas calificaciones: «Si algún muchachón se desenvuelve en las provincias, si se le ve andar de calle en calle, en las carreras y en la chingana, y hallarse presente dondequiera que hay un grupo reunido; si es despierto, altivo, un tanto pillo, apenas tenga quince años que abandonará el lugar y se echará a la ciudad por antonomasia, que ha sido siempre el objeto de sus deseos y de sus castillos de felicidad» ${ }^{11}$.

¿Qué hacen los migrantes en la ciudad? De la Barra, que, mirándolos como intendente, asume la visión clásica de lo que será luego la «cuestión social», los asocia con el aumento de la vagancia, el vicio y el crimen. Sarmiento, en cambio, esboza el tema de la masa suboctipada, el carácter ocasional de sus empleos, signado por la estacionalidad, y la rotación de estos puestos de trabajo, que permite una cierta subsistencia a cada uno en el marco de un crónico exceso de mano de obra. «Hay en Santiago 300 hombres robustos que se ocupan de vender mote; 300 de vender huesillos; 2.000 de vender frutas; 1.000 de vender un par de zapatos cada uno, y millares de hombres sanos que gastan su existencia en ocupaciones que el que las ve practicar se asombra de que puedan proporcionar medios de vivir» ${ }^{12}$. Nuevamente, el enfoque global se complementa con la perspectiva de los sujetos: el migrante ingresa en la «clase de roto raso» y comienza «el aprendizaje de la vida de Santiago; de allí pasará a tomar uno de los muchos oficios que se ha inventado el pueblo para hacer pasar a ser ayer el día presente. (...) Será perero, cirgüelero, uvero, duraznero, en verano; durcero, velero, bollero, en invierno. (...) Un día llegará a ser falte, en cuya profesión, y a merced de su talento, de su viveza, de su elocuencia, podrá vender por diez lo que le cuesta uno y tener el domingo un par de pesos en el bolsillo» ${ }^{13}$.

10 «Santiago», cit.

${ }^{11}$ "La villa de Yungay» (1842), en Obras completas de Sarmiento. I: Artículos críticos y literarios, 1841-1842 (Buenos Aires: Editorial Luz del Día, 1948), p. 201.

12 «Santiago».

${ }^{13}$ «La villa de Yungay», p. 201. 
Al final se esboza el tema de la movilidad, del pequeño ascenso posible que permite saltar un foso, sin embargo ancho, entre los «rotos rasos» y los «bodegoneros y artesanos». Los textos de Sarmiento también abordan con precisión los problemas típicos de este mundo: el valor de la especialización, la competencia de los productos extranjeros, la cuestión de los salarios, la dignidad del trabajo, la integración de los artesanos en la sociedad decente ${ }^{14}$. En este punto, los textos entran en otra zona, pues al referirse a las características más generales de la sociedad, el tono se hace menos preciso y objetivo y las agudas percepciones comienzan a teñirse de ideas, valores, prejuicios y proyectos. El testigo se convierte en testimonio.

\section{EL TESTIMONIO}

Como en casi todas las sociedades urbanas de su tiempo, en la de Santiago convivían, mezclados pero separados, decentes y plebeyos. Las diferencias, profundas, casi insuperables y recíprocamente aceptadas, se establecían según criterios en los que, tanto como la fortuna, pesaban el linaje, la educación, las formas de vida. Ciertamente, ambos sectores no eran homogéneos: un decente pobre podía no ser aceptable como yerno de alguien mejor establecido (como le ocurrió en San Juan a Sarmiento poco antes de emigrar) y nadie confundiría a un artesano con un roto raso. Sin embargo, esas diferencias eran menores: claramente escindidos, ambos sectores participaban de un mundo común, con tradiciones, costumbres, valores y espacios sociales compartido -como las clásicas fiestas- y conformaban un complejo equilibrio, hecho de sumisiones y concesiones, acatamiento general y rebeldía esporádica ${ }^{15}$.

Aunque extranjero y pobre, Sarmiento se identifica en lo fundamental con la gente decente santiaguina, y su visión de la sociedad es, en primer lugar, la de aquélla. Pero lo que da valor singular a su testimonio - y a la vez lo convierte en un testigo excepcional- es su capacidad para trascender las limitaciones de esa visión originaria, desarrollar una pluralidad de perspectivas y articular en sus textos los diferentes puntos de vista.

Está en primer lugar el Sarmiento decente, hijo de una familia tradicional, que asume sus opiniones, sus valores, sus prejuicios. Está luego

14 Véanse «Las maderas» (1842), «E1 salario» (1849), "Aprendices de imprenta» (1849), todos en Obras. X: Legislación y progresos en Chile.

${ }^{15}$ Sobre esta imagen de la sociedad patricia, véase José Luis Romero, Latinoamé. rica, las ciudades y las ideas (Buenos Aires: Siglo XXI Editores, 1976). 
el Sarmiento reformador; el hijo de sus obras, capaz de distanciarse de los decentes, mirarlos irónica o críticamente y, armado con lo mejor del pensamiento europeo, formular un programa de transformación de la sociedad que, sin desechar sus valores y actitudes originarios, los desarrolla y transforma hasta identificarlos con un ideal de racionalidad y progreso universal. Extremando esta línea, hay, finalmente, un Sarmiento capaz de identificarse con ciertos valores económicos y políticos modernos (el trabajo o la democracia), al punto de modificar su visión originaria de los grupos populares y encontrar en ellos elementos progresistas. Es, sin duda, una distinción analítica: no sólo cada perspectiva está siempre unida a las otras, sino que en un mismo texto, párrafo y hasta frase, se modula de una a otra, a veces suavemente, a veces con deliberada brusquedad.

¿Dónde encontraría la democracia un Tocqueville sudamericano (el mismo que Sarmiento evocará luego en Facundo)? «En la venta de zapatos del sábado, el pueblo llamado tal, el pueblo llano, el tercer estado, el pueblo pillo, trabajador e industrioso, en fin, por si no he dicho nada todavía, aquello que nuestras buenas y decentes gentes llaman canalla, plebe, vulgo, muchedumbre, populacho, chusma, multitud, qué sé yo qué otros tratamientos honrosos, se reúne al frente de aquel portal, que es su conquista, a vender sus artefactos, a comprar lo que necesita, a ejercer su industria, su capacidad y su malicia. (...) Allí es donde la democracia se ostenta, a la luz de mil antorchas, activa y orgullosa. ¡Qué estrépito! ¡Qué movimiento! ¡Qué confusión! Allí la igualdad no es una quimera, ni la libertad un nombre vano. Nada de fraques, nada de nobles, ni patrones, ni coches, ni lacayos con galones y penachos, ni clases, ni distinciones, ni calabazas. Igualdad, comercio, industria, todo es una sola cosa, un ser homogéneo, una síntesis; en fin, la república llena de vida y animación, el pueblo soberano, el pueblo rey» ${ }^{16}$.

El tono colorido y humorístico del costumbrista apenas disimula la crítica social, fuertemente teñida de progresismo democrático. El punto de vista político es subrayado por reiteradas alusiones a la Revolución francesa (tercer estado, igualdad, libertad, pueblo soberano, república), que se oponen a nobles (ien Santiago!, donde —ironiza- «somos más nobles que Alarico o Carlomagno»), lacayos, distinciones. El punto de vista económico apunta a los valores del nuevo capitalismo: frente a las formas de vida aristocráticas del ocio y el despilfarro, el pueblo se presenta asociado con la industria, el comercio, el trabajo, que es comparable en dignidad incluso con la más noble tarea del letrado: en Valparaíso «no se piensa, se trabaja». Si bien estas virtudes son atribuibles a la capa superior del

${ }^{16}$ «La venta de zapatos» (1841), en Obras, I, pp. 50-51. 
pueblo, los artesanos y tenderos, en algunos textos se extienden hasta a los «rotos rasos», capaces de prosperar gracias a «su iniciativa».

Pero en seguida, sin transición, aparece el antiguo punto de vista que, sin embargo, tomando distancia, atribuye a «nuestras buenas y decentes gentes». Entre tantas apelaciones, evita la más tradicional y denigratoria para «esos que injustamente llamamos rotos» ${ }^{17}$. Esta forma tradicional de mirar al pueblo aparece corrientemente en muchos otros textos, dominados por la perspectiva decente o moralizadora, en los que, por ejemplo, se reprocha a «nuestra clase trabajadora» que «malgaste miserablemente el fruto de sus faenas en la disipación más vergonzosa» ${ }^{18}$. Aquí, en cambio, domina el tono simpático y optimista: la moderna democracia (por ahora sólo social) y el trabajo productivo, que «son una misma cosa», anticipan la imagen de una sociedad nueva, democrática y capitalista, que consolidará luego de su viaje por los Estados Unidos e incorporará definitivamente a su programa de reformador social.

Enfrente, o arriba, del pueblo está la gente decente. Veámosla en uno de sus escenarios preferidos: la Alameda, durante los festejos patrios del 18 de septiembre, «espectáculo digno de una capital europea». «No entraremos en detalles sobre el Te Deum, sobre las vulgarísimas exhibiciones pirotécnicas en la plaza principal, formación de tropas, paseo a la Pampilla y demás diversiones y ceremonias de regla en todos los aniversarios, que nadie ignora. Sí hablaremos de la mayor ostentación que ha hecho en estos días la capital de su creciente cultura y prosperidad y de las nuevas galas con que ha presentado en bailes y paseos. Es en estos sarios, que nadie ignora. Sí hablaremos de la mayor ostentación que ha llegado Santiago» ${ }^{19}$. He aquí manifiestos los valores — tradicionales y modernos - de una sociedad criolla que se europeíza rápidamente: el lujo del vestuario, las maneras refinadas, la conversación inteligente, todo lo que, despertando el espíritu de emulación, contribuye al refinamiento y marca el grado de cultura y civilización alcanzado por una sociedad. Su ubicación en una fiesta pública, en la que el pueblo, a los costados de la Alameda, es identificado por su apego a las formas criollas, subraya el valor social de la ostentación en una sociedad en la que el espectáculo es parte de la ligazón social.

Sin embargo, el cuadro tiene dos caras, pues «de estas causas nacen, como en todo, bienes y males». Si la ciudad estimula el refinamiento, también «se desarrolla un lujo excesivo, los rentistas dan la ley y tienen que

17 «Las fiestas del 18 de septiembre en Santiago» (1842), en Obras, I, p. 367.

${ }_{18}$ «Un tribuno de la plebe» (1844), en Obras, X, p. 338.

19 «Las fiestas del 18 de septiembre en Santiago», I, p. 365. 
seguirlos por imitación, para no ser menos, los comerciantes, los que viven de un empleo y las familias más acomodadas» ${ }^{20}$. La ciudad ostentosa distrae energías que deberían dedicarse a la actividad productiva y el progreso. Si bien resuena en el fondo la antinomia básica entre la España hidalga y la Europa progresista, más presente está la opinión entre Santiago y Valparaíso, donde «los efectos europeos exhalan un olor a civilización que, esparciéndose por el aire, imprime a todo actividad y movimiento" ${ }^{21}$. A diferencia de Alberdi, Sarmiento elige vivir en Santiago y no en Valparaíso — «esta vida me sería imposible»-, pero el pasaje le permite establecer un término de comparación para fundamentar, puesto en progresista y reformador, su crítica de los valores y formas de vida tradicionales de la gente decente.

Si es aceptable que hacendados y comerciantes asuman los valores hidalgos, esto es inadmisible para el grupo de aquellos pobres que forman las dos terceras partes de la población decente de Santiago. Viven al día; en el mejor de los casos, con un modesto empleo de dependientes o escribientes; en el peor, de expedientes, como a su juicio lo prueba la proliferación de casas de usura. Por su educación, deberían volcarse a las artes y oficios, o por lo menos a aquellos «dignos», como la imprenta, «si no hubiese un vicio radical en sus ideas, que estorba adquirir los medios de industrias honestamente. (...) Hemos visto madres desvalidas desdeñar para sus hijos un aprendizaje en el noble arte de la imprenta, por no desdecir de su pretendido rango, que a fe era muy subalterno» ${ }^{22}$.

E1 «hijo de sus obras», que no desdeñó ser minero, reivindica aquí el valor del trabajo, virtud característica de la moderna ética económica, aunque no ausente de la tradición progresista ilustrada; el mismo trabajo que enaltecía a su madre (aunque - debe señalarse - también el mismo que confirmaba la degradación moral de Quiroga). A partir de él establece sus distancias con la gente decente, pero también indica dónde encuentra el sector capaz de transformar la sociedad: el progreso no vendrá de la masa de artesanos rutinarios ni de los «rotos avisados», sino de los decentes que, como él mismo, superando las limitaciones de su educación y de los valores arraigados, emprendan el camino del progreso. Por esta vía indirecta, lo que empezaba siendo un rechazo frontal de la vieja so-

2.) "La villa de Yungay», I, p. 202.

${ }^{21}$ «Un viaje a Valparaíso» (1841), en Obras, I, p. 133.

${ }^{22}$ «Santiago». El tema es retomado en «Aprendices de imprenta», cit. En «Du* rante el té», en Obras (I, p. 160), al defender el derecho de un artista a ganarse la vida con su arte y no perder por ello el de ser invitado en una reunión social, reitera su crítica a los prejuicios contra el trabajo. 
ciedad concluye con una reforma que, en definitiva, confirma las jerarquías y reafirma sus principios fundamentales.

Este juego, bastante complejo, entre la imagen tradicional y la moderna y crítica, se manifiesta sobre todo ante los modos de relación y conflicto entre ambas partes de la sociedad. El tradicional control de los decentes, que combina fuerza y coerción con variados mecanismos simbólicos, deja, sin embargo, a la plebe zonas de libertad y espontaneidad: «Aquí - en la venta de zapatos- las distinciones sociales no le humillan, no lo insulta la riqueza ni esbirros lo incomodan, ni lo celan importunos vigilantes» ${ }^{23}$. El dominio cotidiano, sólido aunque no omnipresente, se fortalece con momentos de escape periódicos y previsibles, cuando las tensiones se alivian: son las clásicas fiestas en las que, por una noche al menos, las diferencias pueden olvidarse. Este tema - por otra parte clásico- aparece en cuanto novelista, costumbrista, viajero o periodista escribió sobre Santiago: son las chinganas populares, concurridas por los decentes, al igual que los señoritos madrileños gustan mezclarse con chulos y majas; son los juegos de volantines, los festejos del 18 en la Pampilla o la fiesta de Nochebuena. Aun cuando escribe en festivo tono costumbrista, Sarmiento no oculta su desagrado por estas fiestas, enraizadas en una tradición hispana que el progreso, la educación y la moralización deben hacer desaparecer: "Allí —en la Nochebuena-, el populacho cometía mil desórdenes, no se veían más que pleitos, las pedradas silbaban en todas direcciones, arrebataban los pañuelos del cuerpo de las mujeres, sin que las patrullas y serenos fuesen bastante a contener tan horrendos desórdenes» ${ }^{24}$.

Frente a esta forma de encuentro, tumultuosa, desarreglada y deplorable, le resulta ejemplar la que encuentra, sorprendido, en un teatro popular. Aunque se representa una singular versión de misterio sagrado ad usum populi (en la que un anacrónico alcalde aparece en la corte de un no menos anacrónico Herodes con turbante y media luna), el contexto es el adecuado a la idea de Sarmiento de una relación edtucativa y progresista entre ambas partes de la sociedad. Los participantes también se comportan adecuadamente: «En una concurrencia de más de quinientas almas, en que el poncho y el fraque se andan rozando, vimos no sin mucha complacencia reinar el mayor orden, y entre los dandys del lugar, compadritos y artesanos, notábamos un conato asiduo por mostrarse a cual más civil y complaciente.» Si hubo una nota discordante, que requirió de la intervención policial, ésta provino «con vergüenza nuestra

\footnotetext{
${ }^{23}$ «La venta de zapatos», I, p. 51.

${ }^{24}$ «Fiestas de la Nochebuena» (1841), I, p. 163.
} 
(...) de alguno de fraque». Esta convivencia morigerada y pedagógica está muy distante del revoltijo de Nochebuena: no sólo los policías aseguran el orden, sino que una serie de palos y una reja, colocados en la platea, «para separar la gente rota de la gente decente», recuerda a cada uno su verdadera ubicación en la sociedad ${ }^{25}$.

Este equilibrio de la sociedad escindida, hecho de identidades asumidas y atribuidas, de protección y concesiones, de humillación y deferencia, de prédica y espectáculo y también de discreta coacción, que se refuerza con espasmódicas liberaciones, también incluye otra dimensión - cuyo registro es menos común- de sordas y cotidianas resistencias, de apropiaciones y avances sobre el campo del otro, siempre dentro del marco de lo aceptado y permitido. «Nos han dicho que esos que injustamente llamamos rotos se mostraron altamente desagradados en la noche del 17 porque los fuegos no estuvieron buenos; como si los fuegos formaran un derecho político o envolviesen una de esas cuestiones de salarios o de pan que suelen agitar a John Bull» ${ }^{26}$. La misma dimensión conflictiva de lo cotidiano, y de los cambiantes equilibrios de la sociedad patricia, aparecen en la escena de la venta de zapatos. «¿Cuánto valen las botas?... Pregunta indiscreta (...) Las botas no tienen valor intrínseco. En cuanto a calidad y obra, se traen de noche para que mejor se examinen; mas iel precio?, el precio está escrito en vuestro semblante.» Los términos generales de la relación entre el comprador decente y el vendedor plebeyo no están en cuestión, pero las condiciones precisas de un equilibrio concreto - el precio de las botas- son la resultante de una relación tensa, en la que la parte popular, dueña del terreno, está lejos de llevar la peor parte. Cada bota tiene un precio distinto, que el vendedor descubre oyendo una simple frase del comprador o con una «mirada de los pies a la cabeza». No hay dudas de que la venta se hará, pues una vez establecida la relación «ya tiene derecho a unas cuantas pesetas, las que se están aglomerando en su bolsillo. Os ha fijado, y os ha de dar soga hasta que os aburráis de regatear». En otros ámbitos - la plaza, la Alameda, la fiesta patria - la relación entre decentes y populares se establecerá de otro modo, pero en la pila de los zapateros, sin duda, el equilibrio favorece al pueblo, «porque la plaza de Santiago es el forum romano, donde el pueblo es el que manda, el que tiene y el que puede» ${ }^{27}$. Alberto Blest Gana - a quien suele considerarse el Balzac chileno- pre-

${ }^{25}$ «Los misterios de la calle de San Francisco» (1845), en Obras. II: Artículos: criticos y literarios, 1842-1853, pp. 253-264.

${ }^{26}$ "Las fiestas del 18 de septiembre en Santiago», I, p. 367.

${ }^{27}$ «La venta de zapatos», I, p. 52. 
sentó, dos décadas después, una escena casi igual en Martín Rivas, que impresiona, frente a ésta, como sosa y superficial. La comparación revela no sólo la singular sensibilidad social de Sarmiento, sino, sobre todo, su capacidad expresiva.

Este regateo no deja de divertirlo; pero los desbordes de las fiestas populares horrorizan a quien carece de la tradicional tolerancia de los decentes. ¿Han de tolerar los jóvenes decentes los «actos de prostitución» de la Alameda, la «fiesta de algazara» en lugar de la misa y el "rolar entre gente sumida en la embriaguez?». «iNo! —clama admonitorio el reformador-. Abolid tan aldeana costumbre, dejad para la plebe la Nochebuena, hasta que la policía tome medidas activas para prohibir tamaños desórdenes» ${ }^{28}$. La segregación del bajo pueblo, la separación de los ámbitos de recreación decentes y populares, el encierro de aquellos en la «ciudad propia», que caracterizará las actitudes de la elite santiguina en la década del setenta y que corporizará Vicuña Mackenna con su Camino de Cintura ${ }^{29}$, aparecen in nuce en estas líneas.

Por entonces era una voz aislada. Seis años después, en 1849, esa misma voz denuncia problemas sociales más modernos. Por entonces, los ecos del 48 francés han conmovido a los santiaguinos, entusiasmados con la Historia de los Girondinos, de Lamartine. Jóvenes radicales, impulsados por una cierta agitación de los artesanos, comenzaron a pensar en nuclearlos en la Sociedad de la Igualdad y, a la larga, en utilizarlos como ariete contra el gobierno pelucón. Sarmiento - que ya había hecho su experiencia europea y norteamericana y actuaba defendiendo al ministerio - intenta minimizar el problema: «Estamos muy lejos de considerar este asunto como una lucha de clases, como la disidencia entre el rico y el pobre, ni como la aparición entre nosotros de las perturbaciones que agitan hoy a otras sociedades, a menos que el espiritu de partido no quiera forzar meras disidencias entre patrones y oficiales y darles un carácter social que no tienen». Pero más allá de la especiosa argumentación política, se manifiesta su percepción de la emergencia de los problemas sociales modernos, que enfrentan a trabajadores y empresarios, la que confirma con una exposición totalmente ortodoxa de la teoría liberal de los salarios que estaría fuera de lugar si el autor creyera realmente en su afirmación anterior: por más que las coaliciones de los trabajadores logren mejoras salariales, por más que el gobierno proteja el trabajo nacional,

${ }^{28}$ «Fiestas de la Nochebuena», I, pp. 164-165.

${ }^{29}$ Según el proyecto de Vicuña Mackenna, el Camino de Cintura debía separar «la ciudad propia, ilustrada, opulenta y cristiana» de «esa suerte de Cairo infecto», que eran los nuevos suburbios. Cfr. Vicuña Mackenna, La transformación de Santiago, y A. de Ramón, Suburbios y arrabales... 
el mercado inexorablemente impondrá sus reglas ${ }^{30}$. El reformador social adopta un discurso conservador, pero conoce perfectamente el problema que enfrenta. Los dirigentes radicales e igualitarios, en cambio, parecen ignorarlo: en su célebre carta a Francisco Bilbao — considerada el más lúcido análisis de la sociedad chilena de mediados de siglo-, Santiago Arcos, inspirador de la Sociedad, ignora, sin embargo, los problemas de ese artesanado, que debía haber constitudo la sustancia misma de su partido ${ }^{31}$.

En sus formas antiguas -el tumulto de las fiestas- o modernas - el reclamo salarial-, el desgajamiento de los sectores populares era una amenaza, que se agravaba con la acumulación de rancherías y huangulies. Sarmiento reflexiona en términos clásicos: es necesario religar la sociedad, moralizar la parte popular, «hallar un medio de poner en contacto a las clases inferiores de la sociedad con aquellos ciudadanos que se interesan por mejorar su condición; establecer corrientes por donde desciendan hasta ellos las ideas que están ya difundidas en la parte culta, y que un dique insuperable contiene en límites por desgracia muy estrechos» ${ }^{32}$. Por el momento, sus propuestas son las tradicionales: enseñanza de artes y oficios, difusión del ahorro, cursos, periódicos, representaciones teatrales. Se entusiasma inclusive con la propuesta del diputado Palazuelos de reflotar las viejas cofradías y usarlas para educar a los artesanos. Pero a la espera de que madure su gran programa de educación popular, su imaginación le hace concebir formas nuevas: la fiesta del 18 de septiembre, que «ha perdido mucha parte de su carácter político», puede servir para estimular el talento y el amor a la gloria en las clases más bajas de la sociedad». Una combinación de reafirmación de los valores patrios - la que había reclamado al iniciarse en la prensa chilena- con actividades inspiradas en la tradición grecorromana, como los juegos, certámenes y premios, permitiría transformar la «fiesta semanal en la que sólo se satisfacen y promueven los instintos groseros... dándole un objeto de utilidad pública» ${ }^{33}$.

${ }^{30}$ «Salarios», X, p. 220.

${ }^{31}$ Santiago Arcos, Carta a Francisco Bilbao (1852), en Gabriel Sanhueza, Santiago Arcos, comunista, millonario y calavera (Santiago: Editorial del Pacífico, 1956). Cfr. también mi trabajo La sociedad de la igualdad, cit.

32 «Un tribuno de la plebe» (1844), en Obras, X, p. 338.

${ }^{33}$ «Las fiestas del 18 de septiembre en Santiago», I, p. 367. El tema del patriotismo había sido planteado en su primer artículo chileno: «12 de febrero de 1817» (1841). 
«LA MÁQUINA DE APRENDER» ${ }^{34}$

«Premunido del conocimiento de las teorías sociales»—que leía ávidamente-, pero también mirando a su alrededor, este Tocqueville sudamericano ha alcanzado una visión general de la sociedad, sus partes, conflictos y tendencias, y ha elaborado, a partir de ellos, el programa de una sociedad nueva, democrática, industriosa y progresista, en la que los distintos sectores se integren sobre bases nuevas y más firmes. Con ambos ha de escribir Facundo, y luego ha de viajar, para volver a mirar y terminar de dar forma a unas ideas que - me parece- ya están in nuce.

Muchas veces se ha señalado cuánto leyó Sarmiento para lograrlo. E1 mismo ha dejado todas las indicaciones necesarias. Aunque obvio, debe destacarse el trabajo del observador cuidadoso, que va colocando cada cosa recogida en el lugar que la teoría va preparando, y que extrae de cada cosa lo necesario para seguir dando forma a su teoría. No hay situación, persona, objeto o episodio observados que carezcan de algún sentido. Más aún, cada hecho minúsculo está a tal punto cargado de sentido, que toda una realidad muy vasta se expresa en él. Es, sin duda, el historicismo romántico el que lo impulsa, pero es la seguridad de una construcción teórica ya madura, unida a una singular agudeza en la mirada, lo que le permite alardes tales. Así, el portal de la plaza de Santiago encierra todo el sentido de la historia pasada y de la sociedad por construir, pero al mismo tiempo lo muestra a él mismo ubicado entre el pasado y el futuro. "Con la forma mampata de un vejete español de bragas», sus «arcos redondos y chatos» le recuerdan «las ideas que cobijaba una empolvada peluca; pero que se dejaba estar ahí, como se han dejado estar entre nosotros las aplastadas ideas y costumbres de aquella España venerada». Un día, «el hacha y la azada revolucionaria» lo demolieron, como a todo el antiguo orden, y en su lugar se elevó otro, «deslucido e inconcluso, como la práctica de un proyecto de mejora; y por añadidura ruinoso a los diez años, como todas nuestras instituciones; mas, por otra parte, útil para el momento presente, que es lo que lo constituye eminentemente democrático» ${ }^{35}$. Con motivo de un modesto portal, el teórico y reformador desnuda aquí su educación y prejuicios y expone la voluntad de superarlos, sin resignar su espíritu crítico.

${ }^{34}$ La frase es de Carlos Altamirano y Beatriz Sarlo, «Una vida ejemplar: la estrategia de Recuerdos de provincia», en Ensayos argentinos. De Sarmiento a la vanguardia (Buenos Aires: CEAL, 1983), quienes subrayan el valor dado por Sarmiento a la lectura.

${ }_{35}$ «La venta de zapatos», I, p. 50. 
Si esa capacidad de encontrar sentido en todo, de hacer aparecer la «historia profunda» en lo trivial, de desnudarse en un objeto, convierten a Sarmiento en un testimonio apasionante, no es menos cierto que esa cabeza ordenada y estructurada ha desarrollado una agudeza y perspicacia llamativas, que le permiten ver lo que otros no ven y así aprender permanentemente. El movimiento inicial, que buscaba el sentido en lo mínimo, se invierte, y Sarmiento avizora la realidad profunda, todavía escondida, aun para observadores sensibles e inteligentes. Ha visto mejor que el intendente De la Barra el incipiente crecimiento de Santiago y la incorporación de los migrantes a la sociedad; ha entendido mejor que Jotabeche la vida de los nuevos suburbios; ha intuido mejor que Blest Gana los conflictos presentes en la trivial venta de zapatos y ha comprendido mejor que Santiago Arcos la naturaleza de los problemas gremiales de los artesanos y sus potencialidades políticas. Es de sobra sabido que es un gran escritor. Para un historiador, también es una fuente excepcional. 
